Introduction: The science supporting event medicine is growing rapidly. In order to improve the ability of researchers to access event data and improve the quality of publishing mass gathering cases, it would be of benefit to standardize event reports to permit the comparison of similar events across local and national boundaries. These data would support the development of practice standards across settings.

Aim: The authors propose the creation of a publication guideline to support authors seeking to publish in this field.

Method: Derivation study via analysis of published case reports using the Delphi process.

Results: Data elements were inconsistently reported within published case reports. Categories of variables included: event demographics (descriptors of date, time, genre, activity, risks), attendance and population demographics, data related to climate and weather conditions, composition and deployment of an onsite medical team, highest level of care available onsite, patient demographics, patient presentations and measures of impact on the local health care system such as transfer to hospital rates. Of note, there was a high incidence of "missing" variables that would be of central interest to researchers.

Discussion: Approaches to standardizing the collection and reporting of data are often discussed in the health care literature. The benefits of consistent, structured data collection are well understood. In the context of mass gathering event case reporting, the time is ripe for the introduction of a guideline (with accompanying guidance notes and dictionary). The proposed guideline requires the input of subject matter experts (in progress) to enhances its relevance and uptake. This work is timely as there is ongoing work on improving an international event medicine registry. If the evolution of both proceeds in lockstep, there is a good chance that access to a rigorous data set will become a reality.

Prehosp Disaster Med 2019;34(Suppl. 1):s148-s149

doi:10.1017/S1049023X19003327

\section{Medical Activity Training using SDF Ship at Wide Area Disaster}

Dr. Seiji Mimura

Tokushima Prefectural Central Hospital, Tokushima City, Japan

Introduction: We have repeatedly trained to use the SDF ship as a temporary medical facility during acute disasters. The Maritime Self Defense Force has various types of ships: supply ship (Oumei type), transport ship (Osumi type), and escort ship (hinge type, whip type) which has a large hangar and a treatable medical compartment.

Methods: The points of training are collaboration between the SDF and the commander's line of medical personnel, construction of a method of contact with the outside, construction of contact method inside the ship, kind of patient, medical contents, use of medical zone, method of transporting to the ship, method of transporting to the outside of the ship, positioning of the ship in the afflicted area, etc.

Results: Assuming the Nankai Trough Earthquake, the activities of SDF vessels in coastal areas are affected by the extent to which the functions of medical institutions in inland areas are kept, how transportation methods can be secured, and how many injured people there are.

Discussion: As a result of the examination thus far, the range of activities of SDF vessels is limited. The function of the ship is considered to be offshore SCU, hospital evacuation support, etc. Tight collaboration and training with the SDF are necessary in the future.

Prehosp Disaster Med 2019;34(Suppl. 1):s149

doi:10.1017/S1049023X19003339

Medical Measurement Against the Mega-Disaster: The Necessity of Systematization of the Disaster Medicine or the Disaster Medicine Compendium

Dr. Yoshikura Haraguchi ${ }^{1}$, Dr. Yozo Tomoyasu', Dr. Tohru Tsubata ${ }^{3}$, Dr. Tetsu Ishihara ${ }^{2}$, Motohiro Sakai ${ }^{4}$, Iyasu Nagata ${ }^{4}$

1. Keiyo Hospital, Disaster Medicine Compendium Group, Tokyo, Japan

2. Hikifune Hospital, Tokyo, Tokyo, Japan

3. Keiyo Hospital, Tokyo, Japan

4. Disaster Medicine Compendium Team, Japan, Tokyo, Japan

Introduction: The large number of casualties during major or mega-disasters are a global problem.

Aim: The role of medicine against mega-disasters is analyzed from a worldwide perspective.

Methods: Chernobyl incident, the Tokyo Subway Sarin Attack, the 9-11 attack, the Indian Ocean earthquake/tsunami, Hurricane Katrina, the Flu pandemic, the Higashi Nihon Earthquake followed by the Fukushima nuclear plant incident, etc. are critically analyzed, based on the actual medical experiences.

Results: These mega-disasters often have a wide, severe negative influence. Linked catastrophes often form catastrophic circulus vitiosus $(\mathrm{CCV})$ or malignant cycles on a global scale. The typical example is the Chernobyl incident which caused not only many deaths by radiation exposure/thyroid cancer and world anxiety, but also is considered to have contributed to the end of the Eastern European Communism system in 1989 (East Germany) and 1991 (ESSR).

Discussion: Many roles of medical doctors and staff were requested, including creating preventive life-saving systems, in addition to the prevention of mega-disaster measurement to minimize the unhappiness. Moreover, medical ethics and philosophy are important, which were often overlooked. It is necessary for medical care and support to have a broad perspective. Although the classical philosophy of utilitarianism is often accepted without suspicion, it comes with the risk of disregarding vulnerable/weak people. The concept of justice according to John Rawls (USA) and the Minimal Unhappiness Theory by Naoto Kan (Japanese politician) should be considered, too. From such viewpoints, it is our conclusion to urge the establishment of systematic disaster medicine or to compile a disaster medicine compendium. Although the tentative first version was compiled with 22 volumes in 2005, only one-fourth was available in English. The English part increased up to nearly three-fourths by adding several new versions in which the nuclear/biological/chemical 
hazard version, tsunami measurement, and psychological care version are included at the moment.

Prehosp Disaster Med 2019;34(Suppl. 1):s149-s150

doi:10.1017/S1049023X19003340

\section{Mental Health Impacts on People Living in Subdivided Flats in Hong Kong \\ Ms. Angel $W L \mathrm{Ng}$ \\ Hong Kong Jockey Club Disaster Preparedness and Response Institute, Hong Kong}

Introduction: Housing has always been a source of stress for people in Hong Kong (HK), especially to those living in sub-optimal settings. About 210,000 people are forced to live in subdivided flats in HK. Most of these flats cannot meet health standards set by the UN even for prisoners, in terms of the floor space, climatic conditions, lighting, air quality, and ventilation. Fire and public safety equipment are lacking. Most believed that the substandard environment has a negative impact on one's mental health.

Aim: To investigate how the living condition in a subdivided flat affects a person's mental health.

Methods: 104 households living in the subdivided flats in Kwai Tsing, one of the 18 Districts of HK, were surveyed by HKJCDPRI's Collaborating Partner, HKSKH Lady MacLehose Centre in February 2017; while a follow-up study with purposive sampling was conducted in October 2017 to interview 10 households on their mental health status. A mixed Methods was used combining the quantitative Results of the WHO Quality of Life-BREF scale and Depression Anxiety Stress Scale 21, and qualitative Results of face-to-face interviews. Results: $80 \%$ of 104 households surveyed suffered from mental distress. The follow-up study revealed that seven of them displayed signs of depression and/or anxiety, while two were diagnosed with a mental disorder. Distress is proven to associate with the environmental and health risks, including fire and disease outbreak, as well as chronic issues resulting from poor indoor air quality and extreme weather.

Discussion: Low level of perception and preparedness among HK people is making these public health risks more apparent. The already desperate housing and land policy don't seem to offer any help in the near future. Public educations efforts need tremendous enhancement, to engage, mobilize and empower individuals and communities, to actively plan and prepare for future shocks.

Prehosp Disaster Med 2019;34(Suppl. 1):s150

doi:10.1017/S1049023X19003352

\section{Misericord Injuries: Ancient and Modern Dr. Alfredo Mori ${ }^{1}$ \\ St John of God Health Care, Geelong, Australia}

Introduction: The Misericord, or stabbing pike, was a frequently used battlefield implement in medieval times. The misericord was used by battlefield clerics to relieve the suffering of irreparably wounded soldiers. Its cultural parallels include the Roman gladius, the Japanese wakazashi, and the eponymous Liston knife used in pre-Victorian era surgery in England.
Methods: This demonstration will analyze modern misericord injuries in the light of the current epidemic of long knife (or zombie knife) attacks in London and the domestic terrorist threat in Australia.

Discussion: A review of this weapon is pertinent to the projected low-technology, low-impact, and deep-penetrating wounds expected in urban terrorism in Australia and other cities globally. The talk will emphasize field discussion, demonstration, and disarming techniques against modern misericord-type weapons.

Prehosp Disaster Med 2019;34(Suppl. 1):s150

doi:10.1017/S1049023X19003364

\section{A Mixed-Methods Analysis of the Spatial and Temporal Relationship Between Boko Haram Activity and Lassa Fever Incidence in Nigeria 2017-2018 \\ Ms. Joan Concilio ${ }^{1}$, Dr. Gavin Macgregor-Skinner ${ }^{1}$, Dr. Benjamin Suleiman Tswabki ${ }^{2}$, Dr. Eugene Lengerich ${ }^{1}$ \\ 1. Penn State College of Medicine, Hershey, United States \\ 2. Ministry of Health, Jalingo, Nigeria}

Introduction: Two major public health issues facing Nigeria in 2017 and 2018 were the terrorist activity by the Boko Haram Islamist group and an unprecedented outbreak of Lassa fever. Aim: To determine if Boko Haram activity was temporally or spatially related to the incidence of Lassa fever in Nigeria and if so, to identify potential concurrent causes and mitigation measures.

Methods: The study was a mixed-methods design. First, we conducted a secondary analysis of the Armed Conflict Location and Event Data (ACLED) Project for all known Boko Haram activity and of the weekly Nigeria Centre for Disease Control reports for suspected Lassa fever cases. Data were analyzed for January 2017 through June 2018. The ACLED data were spatially overlaid with suspected Lassa cases for each of Nigeria's 36 states. Secondly, we conducted interviews with six aid workers in Nigeria regarding Boko Haram activities and Lassa fever cases.

Results: In the study period, 596 Boko Haram activities occurred in 13 states (36.1\%): 416 in 2017 and 180 between January and June of 2018. During the same period, 3,137 suspected Lassa cases were reported from 21 states (58.3\%): 1,022 in 2017 and 2,115 in January through June 2018. Only one state, Sokoto, was unaffected by either issue. Aid workers reported a positive relationship between Boko Haram activity and increased negative health outcomes.

Discussion: The investigation found little geographic overlap in Nigeria between Boko Haram activity and the 2018 Lassa fever outbreak, suggesting independence of these two issues. However, unmeasured factors, such as public fear and mistrust of governmental activities, may affect both issues. It is also critical to note that widespread co-occurrence ( $97.2 \%$ of 36 states) of these two issues presents significant public health, medical, and security challenges for Nigeria, calling for overarching solutions such as governmental stability and economic stimulus.

Prehosp Disaster Med 2019;34(Suppl. 1):s150

doi:10.1017/S1049023X19003376 